\title{
The Best is Yet to Come
}

\author{
Allahbadia Gautam N.
}

Published online: 29 January 2014

(C) Federation of Obstetric \& Gynecological Societies of India 2014

Take up one idea. Make that one idea your life - think of it, dream of it, live on that idea. Let the brain, muscles, nerves and every part of your body, be full of that idea, and just leave every other idea alone. This is the way to success. -Swami Vivekananda

Samuel Taylor Coleridge, in The Friend (1828), wrote: "The dwarf sees farther than the giant, when he has the giant's shoulder to mount on." Against this notion, Friedrich Nietzsche argued that a dwarf (the academic scholar) brings even the most sublime heights down to his level of understanding [1]. In the section of Thus Spoke Zarathustra (1882) entitled "On the Vision and the Riddle," Zarathustra climbs to great heights with a dwarf on his shoulders to show him his greatest thought. Once reaching there, however, the dwarf fails to understand the profundity of the vision, and Zarathustra reproaches him for "making things too easy on himself." If there is to be anything resembling "progress" in the history of philosophy, Nietzsche in "Philosophy in the Tragic Age of the Greeks" (1873) writes, it can only come from those rare giants among men, "each giant calling to his brother through the desolate intervals of time." [1].

The Journal of Obstetrics and Gynecology of India is one of the most widely read Medical Journals in the world today with a subscription database of over 28,000

Allahbadia G. N. (ه)

Rotunda-The Center for Human Reproduction, 36 Turner Road, \#101, 1st Floor, B Wing, Bandra (W), Mumbai 400 050, India

e-mail: gautam@rotundaivf.com
Gynecologists and an estimated readership of over 35,000 doctors globally. The journal has had a lineage of giants amongst academicians as Editors, and I honestly feel like a dwarf sitting over the shoulders of past giants who have selflessly taken this Journal to its present-day avatar. I have just one goal in my tenure to get the academic standard of our journal a notch higher and get MEDLINE to index the journal. Two issues that are hampering our indexing with the National Library of Medicine (NLM) database are (i) quality of original research papers, and (ii) plagiarism.

The World Association of Medical Editors (WAME) defines plagiarism as [2]:

"The use of others' published and unpublished ideas or words (or other intellectual property) without attribution or permission, and presenting them as new and original rather than derived from an existing source."

I thought it prudent to begin my tenure with an Editorial on good practices in Medical publishing. Plagiarism can be detected at the level of the reviewer or the editor. The reviewer is a facilitator both for the editor and the author. Depending on the reviewer and editor's judgment, subtle forms of plagiarism, if unintentional, sometimes may not be labeled as scientific misconduct or may not require a legal sanction. The reviewer may simply point out the error and instruct the author to amend it. However, in its more severe forms, especially when it is intentional, plagiarism is considered a serious offence. If an author is found guilty of such an offence, then his article may be retracted. The 
journal's editorial board may issue a publication ban on him. The case of plagiarism may be reported to his employers and/or the professional bodies that the author may be a member of. Once this happens, it could lead to loss of funding for his research, loss of professional dignity, and even loss of employment.

SM Sapatnekar, in an editorial published in the Journal of Association of Physicians of India [3], points out that a lot of plagiarism occurs in the medical field because of the "publish-or-perish mantra" adopted by researchers. Today, with the advancement of the Internet, plagiarism seems to have increased manifold. "Cut-copy-paste" seems to be happening across the world and is significantly prevalent in our community as well. We have to understand that though technology makes plagiarism easy, it also makes detection of plagiarism even easier. There are both paid and free online softwares that can easily detect even short phrases that are copied verbatim from the original source [4-7]. All the editors and reviewers of our Journal have access to proprietary antiplagiarism software since last year.

The American Medical Association Manual of Style [8] describes mosaic plagiarism as "borrowing the ideas and opinions from an original source and adding few verbatim words or phrases without crediting the original author. In this case, the plagiarist intertwines his or her own ideas and opinions with those of the original author, creating a confused, plagiarized mass." This is the more common form of plagiarism.

Duplicate or redundant publication may be seen in several forms $[9,10]$. The same study sample, control data, or study outcomes may or may not be presented. Sometimes, writers use the same tables or figures that may have appeared in previous publications. Another common form of self-plagiarism is "salami slicing." Instead of publishing a large study as a single article, sometimes authors "slice" it into several smaller articles.

The Editorial board will stand firm to improve the academic content and weed out plagiarism so that we can have a publication, which will be the preferred journal for Indians globally to submit their original research. This will happen faster if we are indexed in MEDLINE. What does this mean?

MEDLINE, the principal online bibliographic citation database of NLM's MEDLARS system, is used internationally to provide access to the world's biomedical journal literature. The National Library of Medicine uses an NIH- chartered committee, the Literature Selection Technical Review Committee (LSTRC), to review all new biomedical and health journal titles and recommend those to be indexed for MEDLINE. Scientific merit of a journal's content is the primary consideration in selecting journals for indexing. The validity, importance, originality, and contribution to the coverage of the field of the overall contents of each title are the key factors considered in recommending a title for indexing. In addition, the quality of the layout, printing, graphics, and illustrations are all considered in assessing a journal.

Overall, about $20-25 \%$ of the titles reviewed are selected for indexing. Rating scores range from 0 to 5 . Currently, a title must receive a score of 3.75 or greater to be selected for indexing. It is estimated that there are about 13,000-14,000 biomedical titles currently being published throughout the world. About 5,300 titles are currently indexed and included in the MEDLINE database.

Let us join hands in taking the journal to the next level. We owe this to the next generation of the Indian Gynecologists and to our country.

\section{References}

1. Nietzsche FW, Ansell-Pearson K, Large D. Philosophy in the tragic age of the Greeks. The Nietzsche Reader. Malden: Blackwell Publications; 2006. pp. 101-13.

2. World Association of Medical Editors. Publication ethics policies for medical journals. http://www.wame.org/resources/publicationethics-policies-for-medical-journals. Accessed 31 July 2009.

3. Sapatnekar SM. Plagiarism. J Assoc Physicians India. 2004;52: 527-30.

4. Weeks AD. Detecting plagiarism: Google could be the way forward. BMJ. 2006;333:706.

5. Chaudhuri J. Deterring digital plagiarism, how effective is the digital detection process? Webology, 5(1), Article 50. http://www.webology.ir/2008/v5n1/a50.html.

6. Bilić-Zulle L, Frković V, Turk T, et al. Prevalence of plagiarism among medical students. Croat Med J. 2005;46:126-31.

7. Zhang H. Cross check: an effective tool for detecting plagiarism. Learn Publ. 2010;23:9-14.

8. Iverson C, Flanagin A, Fontanarosa PB, et al. American Medical Association manual of style. A guide for authors and editors. 9th ed. Philadelphia: Williams and Wilkins; 1998. p. 104-3.4.2.

9. Cicutto L. Plagiarism: avoiding the peril in scientific writing. Chest. 2008;133:579-81.

10. Johnson C. Repetitive, duplicate, and redundant publications: a review for authors and readers. J Manip Physiol Ther. 2006;29: 505-9. 